\title{
The Emotional Flow Hypothesis in Entertainment-Education Narratives: Theory, Empirical Evidence, and Open Questions
}

\section{Yotam Ophir, Angeline Sangalang, and Joseph N. Cappella}

Pixar's 2009 animation hit Up began with a touching collage of scenes portraying different stages in the long-lasting, loving relationship between the shy Carl and the extroverted Ellie. The first ten minutes of the movie are an emotional rollercoaster. We witness their hilarious first encounter as two eight-year-old kids, when Carl is shocked by the energetic Ellie.

Y. Ophir $(\bowtie)$

University at Buffalo, The State University of New York, Buffalo, NY, USA e-mail: yotamoph@buffalo.edu

A. Sangalang

University of Dayton, Dayton, OH, USA

e-mail: asangalangl@udayton.edu

J. N. Cappella

Annenberg School for Communication, University of Pennsylvania, Philadelphia, PA, USA

e-mail: joseph.cappella@asc.upenn.edu

(C) The Author(s) 2021

L. B. Frank, P. Falzone (eds.), Entertainment-Education Behind the Scenes, https://doi.org/10.1007/978-3-030-63614-2_7 
Seeing the two plotting adventures together is uplifting. Seeing them as young adults kissing at their wedding and growing old in a modest house, saving pennies in the hopes of someday affording their dream vacation at the majestic Paradise Falls is heart-warming. And finally, seeing the old Ellie in her hospital bed, quietly handing her husband their shared adventure book, implying he will continue the journey without her, then seeing Carl alone at church at Ellie's funeral, is nothing less than heart-wrenching and devastating. No viewer, young or adult, will be blamed for shedding tears as Carl walks back to his now-lonely home for the first time. The movie structured the death scene as the culmination and conclusion of a happy, funny, and inspiring journey. Would our empathy for Carl be as strong if we had not witnessed the moments that preceded it? Would we cheer for him with the same solidarity and dedication if the slow and somber piano accompanying him to the funeral were not in such dramatic contrast to the cheerful music at his wedding night? The theory of emotional flow suggests that we would not, and our attempt to test its premises in the area of entertainment-education (EE) is at the heart of the current chapter.

\section{The Pivotal Role of Emotions in Narrative Persuasion}

Emotions play a central role in decision-making and behavior (Bechara, Damasio, \& Damasio, 2000; DeSteno, Gross, \& Kubzansky, 2013), and to the extent that persuasion is a kind of decision-making, the inclusion of emotional cues can make a message more persuasive (Nabi, 2002). This is particularly true for narrative messages (Oatley, 2012), where readers and viewers are wrapped into the story's world (Green \& Brock, 2000) and form emotional connections with characters (Cohen, 2001). A part of what makes messages in general (Eagly \& Chaiken, 1993), and stories (Oatley, 2012), and EE narratives particularly (Wang \& Singhal, 2016) effective and persuasive is their ability to create and maintain engagement. Emotions often play a pivotal role in securing and maintaining engagement with plots and characters.

Emotions are temporary states representing affective psychological and physiological (Nummenmaa, Glerean, Hari, \& Hietanen, 2014) reactions to an external stimulus (Nabi, 1999; Ortony, Clore, \& Collins, 1990). 
While emotions can be influential in non-narrative messages as well (Eagly \& Chaiken, 1993), their role is especially prominent in stories due to the relationships between readers and characters who are involved in emotionevoking story-events (Dunlop, Wakefield, \& Kashima, 2008; Gerrig, 1993; Scheff, 1979). For example, emotional reactions can mediate the effect of narratives on attitudes (Mazzocco, Green, Sasota, \& Jones, 2010) and can increase interpersonal discussions following exposure to messages (Dunlop et al., 2008).

Traditionally, studies looking into the effects of emotional cues on persuasion have focused on the effect of single specific (called "discrete") emotions in message, for example the effect of creating fear (Witte \& Allen, 2000). Other studies examined whether messages using multiple emotions are more persuasive than those using only one emotion (Dillard \& Nabi, 2006). Importantly, both approaches ignored the possibility that it is not the use of specific emotions that increase persuasiveness, but rather the move between emotions.

Based on that notion, two communication scholars, Robin Nabi (2015) and Melanie Green (Nabi \& Green, 2014) have recently suggested that instead of focusing on static emotions, it might be beneficial to explore the effect of emotional flow, "the evolution of emotional experiences over the course of exposure to a health message" (Nabi \& Green, 2014, p. 143). Arguably, nowhere is the role of emotions more central to processing and experience of messages than in stories (Oatley, 2002), and indeed, Nabi and Green (2014) hypothesized that emotional shifts presented throughout stories could be particularly important for persuasive narratives. An example of the emotional shift in narratives is the typical story structure of suspense, where a protagonist's happiness and well-being are under threat due to some event and are restored only at the end of the plot (Archer \& Jockers, 2016; Fitzgerald, Paravati, Green, Moore, \& Qian, 2019). For example, in an episode of HBO's Sex and the City, a character (Samantha) was asked by a romantic partner to be tested for HIV. She first expresses surprise at the request, then fear and nervousness around taking the HIV test, and finally a relief after learning she does not have HIV (for a discussion of the persuasive effects of this particular narrative, see Moyer-Gusé, Chung, \& Jain, 2011). 


\section{Why Emotional Shifts Are Expected to InCrease Engagement and Persuasion}

There are multiple reasons to expect emotional shifts to affect engagement and, consequently, persuasion. One explanation has to do with resistance to persuasion, and particularly rejection of strong negative messages (Moyer-Gusé, 2008). For example, if a story portrays the frightening consequences of smoking through a character who got sick with cancer, readers, especially smokers who are well-invested in the character's situation, may reject the message to avoid coping with its implications for themselves. If, however, the same character is shown recovering from her disease after quitting smoking, the hope resulting from one's ability to fight the detrimental effects of smoking may allow readers to be more open to the scary message preceding it. In this way, the effect of the message according to the emotional flow hypothesis (Nabi \& Green, 2014) could arguably be the result of a shift in the emotional state of the audience from fear to relief or hope (Witte, 1992).

The second explanation, which is at the heart of our discussion in this chapter, has to do with the expected effect of emotional shifts and flow on engagement. The persuasiveness of narratives is the result of their ability to involve audiences with characters and plots (for a meta-analysis, see Shen, Sheer, \& Li, 2015). Involvement with narratives, often called transportation (Green \& Brock, 2000) or narrative engagement (Busselle \& Bilandzic, 2009), is characterized by an investment of mental and cognitive resources into following plotlines. When one's attention is dedicated to plots and characters, they are less likely to resist and argue with the story's messages and more likely to accept them (Brehm \& Brehm, 1981; Slater \& Rouner, 2002). During a process known as identification, the reader temporarily adopts the point of view, motivations, and emotions of the character (Cohen, 2001) and as a result are less motivated to question the character's thoughts, actions, and messages (Moyer-Gusé, 2008). For example, a viewer who identifies with a television character who faces a health threat is more likely to feel vulnerable to the disease and to accept the show's messages (Moyer-Gusé et al., 2011).

Maintaining engagement with stories, especially long ones, could be challenging, and one's attention might drift from the story's world back to the real world if the reading experience is interrupted, or when the story is just not well-written or interesting (Tal-Or \& Cohen, 2010). Shifts in stories' emotional states could prevent boredom and motivate 
readers to keep up with the plot (Nabi \& Green, 2014). The need for emotional stimulation could be explained by arousal theory (Berlyne, 1960). Arousal is increased psychological and physiological reaction to stimuli, that could be measured via brain activation, other physiological changes (e.g., heart rate), or self-reports. According to this theory there are optimal levels of arousal for individuals at a given time, and lower than optimal levels of arousal can lead individuals to seek stimulation. In the context of a story, reliance on one emotion throughout a story may not suffice to hold readers' attention and engagement. Of course, having too many emotional shifts in one story could also come at the expense of coherence and may harm immersion. However, the optimal number of shifts has yet to be tested in experimental studies.

Going back to the Sex and the City example, the emotional flow hypothesis argues that viewers' interest and engagement with the show is maintained by emotional changes expressed by the characters that are experienced vicariously by the audience (Jose \& Brewer, 1984; Nabi \& Green, 2014). Viewers who identify with Samantha are expected to share her emotions and wish for her to overcome her obstacles and achieve her goals (Cohen, 2001). Samantha's (and the audience member's) shifts between experiencing fear and hope maintain viewer attention and engagement with the show; people who are more strongly transported into a story's world tend to accept its messages more than those who are less engaged with it (de Graaf, Hoeken, Sanders, \& Beentjes, 2012; Green \& Brock, 2000; Shen et al., 2015).

\section{Does Empirical Evidence Support the Emotional Flow Hypothesis?}

The emotional flow hypothesis makes common sense in that good stories often move between emotional states (Gao, Jockers, Laudun, \& Tangherlini, 2016). Yet, for the hypothesis to be used as a practical tool for designing effective EE messages, it should be tested to learn whether evidence supports the argument that emotional shifts in stories can increase audiences' engagement (compared to stability, or no emotional changes). To date, only a few attempts have been made to test the theory. Of these, very few provided preliminary and limited support for emotional flow effects. For example, Fitzgerald et al. (2019) examined the effects of stories of resilience and hope in the face of challenges, a story type they 
named "restorative narratives." They found that exposure to restorative narratives, shifting from negative to positive emotions, yielded higher levels of prosocial behavior than negative-only narratives. Similar results were found in other narrative (Ray, Arpan, Oehme, Perko, \& Clark, 2019; Rossiter \& Thornton, 2004) and non-narrative (Guido, Pichierri, \& Pino, 2018 ) contexts. A potential explanation might have to do with people's tendency to identify more easily with others experiencing adversity rather than good fortune (Royzman \& Rozin, 2006). When those with whom you identify experience challenges, you wish to follow the plot to learn how they overcame them (Cohen, 2001). However, these studies looked at very specific types of emotional flow and did not examine the manipulation of flow systematically.

At the same time, other studies, including our own set of experiments (Sangalang, Ophir, \& Cappella, 2019) failed to provide empirical support for the notion that emotional flow enhances engagement and persuasion. In fact, some studies found short EE stories consisting of only one consistent emotion to be more engaging and persuasive than those consisting of emotional shifts (McAllister, 2020). In the next sections we detail the work our team has conducted in the context of tobacco control and misinformation (Cappella, Maloney, Ophir, \& Brennan, 2015) in order to test emotional flow effects in entertainment narratives. We describe the EE story we created, the manipulation and measurement of emotional shift and flow, summarize our findings, and conclude by considering the implications for EE practitioners looking to implement emotional cues into their persuasive stories and messages.

\section{Designing a Study of Emotional Shifts in a Tobacco Control Context}

In two experimental studies we conducted, we attempted to examine the full model of effects stated in the emotional flow hypothesis (Nabi \& Green, 2014). First, we expected that readers of stories will experience emotions similar to those expressed by the main character. If the character goes through emotional shifts, we expected readers to report going through them too. Second, we expected readers of stories with emotional shifts to report higher levels of engagement with the stories and the main character than those reading a story with no shifts. Finally, as the goal of $\mathrm{EE}$ is to enhance persuasion, we tested whether stories with emotional 
flow were better at changing readers' beliefs about a health topic. Specifically, we tested whether stories with emotional shifts better educated people about the misleading nature of organic tobacco products (Gratale, Maloney, Sangalang, \& Cappella, 2017).

In our first study, a national sample of 385 current smokers, who had smoked at least 100 cigarettes in their lifetime (169 females; 332 nonHispanic whites; 197 college graduates) between the ages of 21 and 65 ( $M$ $=38.8, S D=11.0$ ), read the story described above before answering questions about their reading experience and their opinions about organic tobacco. For the experiment, we wrote our own text narrative of about 1000 words. A challenge for EE narrators is to mask or at least deemphasize the persuasive intent of the text to increase engagement with the story and characters, and reduce potential resistance from readers, as those who feel pressured to change their beliefs and behaviors may reject the message to maintain their freedom of choice (Brehm \& Brehm, 1981; MoyerGusé, 2008). We, therefore, decided to wrap our persuasive message about the misleading nature of organic tobacco within a romantic story. To increase engagement and persuasiveness, we made the story more vivid (Ophir, Brennan, Maloney, \& Cappella, 2017) by providing rich details about the story's setup and events. For example, we situated the events in a late night in New York City, and specifically at a real bar, Eli's Night Shift on 79th street on the Upper East Side. The additional detail contributed to the realism of the story and made it seem more like a real romantic story and less like a public service announcement.

The story we told was thus not about tobacco but about a young woman (the narrator), who is a former smoker and goes on a first date with a man named Eric. During dinner, the two discuss topics such as local art and their workplaces; eventually Eric invites the narrator to smoke with him outside. The narrator contemplates his offer and decides to reject the invitation, as she quit smoking and wanted to avoid "falling down that rabbit hole again." However, Eric claims that "these are not regular cigarettes. They're not nearly as bad for your lungs." Eric adds more inaccurate claims about organic tobacco cigarettes, claims that were found to be prevalent among smokers and manufacturers of organic tobacco (Gratale et al., 2017; Malson, Lee, Moolchan, \& Pickworth, 2002). The narrator hesitates, and here we connected her decision to the date itself to mask the persuasive nature of the story. She decides to smoke with him and trust him on the safer nature of organic tobacco, explaining to herself that "the date was great up to this point and I didn't want to lose the chance just 
because of a smoke." The couple smokes together, gets back into the restaurant, and part ways outside after deciding to go on a second date in the upcoming days.

At this point in the story we manipulated emotional shifts, as different readers were randomly assigned to read a different ending. Participants were randomly assigned to one of seven conditions, six of which included the EE narrative described above. Since the organic cigarettes were presented by Eric as if they offered a hope for smokers who wish to continue their habit while reducing detrimental consequences, the state of hope thus served as the initial emotional state from which emotional shifts stem. The narrator accepts his offer, smokes with him, their dinner continues, and after the two characters part ways, story endings differed based on condition. In the No-Correction condition, the narrator walks home, reading information about artworks they had discussed before. In the Non-emotional Correction condition, she searches out and reads corrective information about the cigarettes online without expressing any emotional response to what she reads. In the other conditions, the narrator reacts emotionally in response to the corrective information by expressing anger over her being deceived into smoking (Hope-to-Anger Ending condition), sadness for people who are misled into smoking (Hope-to-Sadness Ending condition), fear over the power of misinformation to draw people to smoking (Hope-to-Fear Ending condition), and happiness over being able to make the right decision to read more and learn the truth (Hopeto-Happiness Ending condition). Participants in a seventh No Stimulus Control condition completed the questionnaire without being exposed to any story. The expression of emotions was explicit (e.g., "it makes me sad that deceptive information can pull people like me back into smoking”).

Importantly, the characters did not simply express emotional reactions for the sake of including emotional shifts as an experimental manipulation. Instead, the narrator's reactions were directly tied to the misinformation and its correction, that is, to the central argument made through the story. For example, when the narrator expressed anger, that anger was directed toward the tobacco companies and their misleading messages, not toward Eric, her date, whom she actually liked in all experimental conditions. When the narrator expressed hope, it was directed toward the potential of finding a less harmful substitute for smoking. In that way, we attempted to ensure that emotional appeals did not distract, but rather emphasized, our main message. In addition, the narrative explicitly stated which emotions 
the character went through, making it easier for readers to identify emotional shifts in the story.

Engagement is a complex, multi-faceted phenomenon, and in order to capture different aspects of it, we used a battery of preexisting scales often used to assess engagement with EE stories (Murphy, Frank, Moran, \& Patnoe-Woodley, 2011), including transportation (Green \& Brock, 2000), identification (Cohen, 2001), narrative engagement (Busselle \& Bilandzic, 2009), perceived realism (Cho, Shen, \& Wilson, 2012), and enjoyment. To assess the effects of emotional flow and engagement on persuasion, beliefs about organic cigarettes were measured using items based on realworld misbeliefs about organic tobacco (Gratale, Sangalang, Maloney, \& Cappella, 2019). All were measured on a seven-point scale (strongly disagree to strongly agree).

The main challenge we faced was the need to measure whether or not participants experienced emotional flow in response to emotional shifts in the text. For that purpose, we designed a measurement procedure that could measure whether readers noticed the emotional states and shifts the characters went through, and whether they experienced these emotions themselves. We detail the procedure here for others to adopt it in future studies. First, participants were asked: "As the story moved from beginning to end, I felt..." (1: a lot more hopeful to 5: a lot less hopeful). The same was asked about happiness, anger, fear, surprise, and disgust. This question does not measure emotional shift in just any direction, but rather specific emotional shifts consistent with the story participants read. Next, the participants were asked the same series of questions for each emotion for the narrator (e.g., "As the story moved from beginning to end, the narrator (the main female character) felt") and for Eric (e.g., "As the story moved from beginning to end, Eric felt..."). Last, and important for our analysis, participants were asked for each emotion (happiness, anger, etc.), "Thinking again about your own experience, how did you feel at the end of the story" with answers ranging from 1 (strongly disagree) to 5 (strongly agree).

\section{What We Found}

For brevity, we keep the technical details of our analysis here to a minimum. Interested readers may obtain the full analysis from the authors. First, we learned that readers were able to identify the emotions and shifts the characters went through. For example, participants who read the 
angry ending story indicated that the character was angrier at the end of the story than at its beginning. Readers of the angry story were also more likely to indicate the narrator was angry at the end than readers of stories in other conditions. As expected, participants in different conditions did not report different emotional states for Eric's character (congruent with the fact that his character did not change emotions in any of the stories).

Second, we found that readers who strongly identified with the narrator also tended to share her emotional states. For example, participants reading the angry ending version reported feeling higher levels of anger at the end $(M=3.3, S D=1.2)$ than those reading the No-Correction story $(M=2.3, S D=1.5)$, and this difference was statistically significant $(p<.01)$. Similar patterns were found for other emotions (e.g., the condition where the narrator expressed sadness at the end yielded more sad responses from readers than the No-Correction story). Those reading stories with no emotional shift expressed higher levels of happiness and hope, consistent with the narrator's emotions in these stories.

Third, as opposed to our theoretical expectations, we found no effect of emotional shifts on reported engagement with the story or the characters. Specifically, there were no differences between conditions on transportation, identification, or narrative engagement. Results were virtually the same when we looked at differences between specific conditions (e.g., sad ending vs angry ending) or when we collapsed conditions and broadly compared stories with and without emotional shifts. In sum, this essential piece of the emotional flow hypothesis was not supported despite reports that showed readers' emotions varied in predictable ways. Variation in emotion was not associated with variation in engagement.

Fourth, we examined story effects on beliefs about organic tobacco. Multiple regression analysis, controlling for different types of engagement as well as demographics, showed that narrative engagement was the strongest predictor of story-consistent beliefs $(\beta=.6$, all reported effects were significant, $p<.01)$. However, against expectations, other variables in the model predicted beliefs that were less consistent with the story (i.e., more positive toward organic tobacco), including transportation $(\beta=-.4)$, identification $(\beta=-.2)$, and enjoyment $(\beta=-.3)$. The variables explained $57.3 \%$ of the variance in beliefs. These surprising results, and more importantly, the lack of significant relationships between emotional shifts and engagement, led us to design a follow-up study.

In the second study, we tried to understand why emotional shifts did not enhance engagement and why engagement tended to increase 
pro-organic tobacco beliefs. For the former, we attempted to bolster the manipulation of emotional shifts. In our first study, the narrator expressed one discrete emotion at the end of the story. In the second study, we created stories that ended either with no emotional shift or with a shift that was expressed by a combination of negative emotions (angry, sad, and fearful reactions). To address the surprising direction of effects on beliefs, we tested whether participants in our first study who strongly identified with the narrator expressed more pro-organic tobacco beliefs due to vicarious cognitive dissonance beliefs (Bandura, 1986; Festinger, 1962). In short, the narrator in our original study accepted Eric's suggestion and smoked with him. Readers who strongly identified with her were perhaps inclined to dismiss the arguments against organic tobacco to justify her behavior or avoid feeling uncomfortable with her misguided behavior. This concern is particularly important in the context of health EE messages, where the behavior depicted is highly relevant and consequential to readers (O'Keefe, 2013). In our case, the plausibility of dissonance is especially high since the readers were smokers themselves.

As opposed to the first study, in the second study participants (national sample of 586 smokers, 347 females; 500 whites, 230 college graduates between the ages of 18 and $65, M=46.6, S D=12.2$ ) were randomly assigned to one of six conditions, all of which were edited variations of the narrative used in the first study. In half of the conditions, the narrator accepted Eric's offer and smoked with him. In the other half she politely refused and waited for him to return from the smoking break. For each of these stories (smoking and not-smoking options) we wrote three versions: one where the health misinformation is not corrected, one where it is corrected without emotional reaction from the narrator, and one where the narrator expresses the combined strong negative emotions. We also modified the belief scale a bit to be more consistent with the exact beliefs expressed in the story by Eric.

The results of the second study were largely similar to those of the first. Once again, we found no significant differences between stories with and without emotional shifts on identification or transportation. In addition, our speculation that the surprising effects of engagement on beliefs was due to the narrator modeling the negative smoking behavior was not supported, as analysis showed no differences on beliefs between participants in the modeling $(M=3.6, S D=.1)$ and no-modeling $(M=3.7, S D=.1)$ conditions. Modeling did not influence the relationship between emotional shifts and engagement (i.e., there was no interaction between the 
two). On average, as was the case in the first study, we found that participants who reported higher levels of transportation also reported more positive beliefs $(\beta=.2)$ toward natural tobacco products (i.e., beliefs that were less consistent with the story, though the effect was small and explained only a little of the variance in beliefs about organic tobacco). Last, we found no evidence that emotional shifts affected engagement and then engagement affected beliefs (i.e., no evidence for mediation).

In short, the results of both of our studies failed to support the argument that emotional shifts increase engagement with the plot or characters, and that engagement, in turn, increases story-consistent beliefs. This conclusion was supported by the fact that our participants did notice the emotional changes the character went through, and also reported going through emotional changes themselves. The results and conclusions were virtually the same when using discrete emotions and a combined negative emotion and whether the narrator did or did not smoke with Eric.

\section{Lessons Learned and Best Practices}

The emotional flow hypothesis may ultimately be a useful approach for making EE stories more engaging and persuasive. However, at this time, empirical evidence from experiments, including the two reported in this chapter, fails to provide support for its feasibility and effectiveness, at least in short textual stories. Our findings could shed light on some challenges that need to be taken into consideration in future attempts to implement emotional shifts in EE stories and point toward several possible solutions.

First, the manipulation and measurement of emotional shifts and flows is complicated and requires particular attention and care. For manipulation, we opted to use explicit expressions of emotional states. While our readers were able to successfully report noticing these changes, it could be the case that the explicit nature of emotions limited their effectiveness. EE content designers may opt in the future to deliver emotional shifts through "showing, and not telling." As for measurement, we suggested a streamlined procedure for measuring multiple aspects of the flow, including evaluation of whether readers noticed what emotional shifts the characters experienced, and whether they themselves experienced them too, which could be used in future studies. Yet, our findings, as well as other's (McAllister, 2020), suggest emotional flow within short EE texts may not be useful, and at times even detrimental. It could be the case that emotional shifts and flows are necessary to hold audiences' attention over 
90-minute movies or 400-page books, but that the same effect is absent when reading a 1000-word story. These studies suggest that for short stories the use of a single, consistent emotion actually increases engagement and persuasion. Our ancillary analyses (not detailed here) suggested these stories are experienced as more realistic than those including emotional shifts in a shorter space. Emotional shifts may therefore need to be reserved for longer messages. Longer stories may require more than one emotional shift (as used here) to maintain audiences' attention. We believe that studies relying on longer texts will need to develop different measurement tools, and perhaps replace our one-time measurement at the end of the story with assessments of emotional experiences in multiple points throughout the narrative.

A second challenge is determining the order and direction of the emotional shift. In our study, the story first invoked hope, which was then replaced with negative emotions. This emotional shift, at least in our studies, did not yield increased engagement and persuasion. Other researchers managed to achieve more persuasive results with stories shifting from negative emotions to positive ones (e.g., using the restorative narrative structure, see Fitzgerald et al., 2019). However, not all studies using similar shifts replicated; McAllister (2020) showed an advantage for singleemotion stories over restorative ones. While the shift from negative to positive emotions seems more promising at the moment, more research is needed to further support this recommendation.

A third challenge stems from the fact that EE stories often introduce multiple main characters, some of which may experience different and even contradicting emotions. In one of the earliest EE frameworks, the Sabido Methodology proposes EE narratives are successful when they contain characters modeling different positive, negative, and transitional journeys (Poindexter, 2004). For example, in our story, some readers, especially smokers who have a motivation to believe organic cigarettes are healthier, may have identified with the male character, Eric, and not with the female narrator. To ensure readers are being influenced by the intended and not by other unintended emotional arcs, EE practitioners should take steps to promote identification with the protagonist and not with other characters. In our study we did so using first-person perspective that was found to focus identification on the narrator (de Graaf et al., 2012). Other researchers manipulated the background information and history of characters (Tal-Or \& Cohen, 2010) and similarity (Kim, Shi, \& Cappella, 2016). 
Finally, practitioners implementing emotional flows should consider a few ethical implications. Even though we debriefed participants at the end of the study and provided them with additional information about the detrimental health effects of organic tobacco, misinformation studies suggest the exposure to misleading information may cause harm even if followed by a correction (Lewandowsky, Ecker, Seifert, Schwarz, \& Cook, 2012). Some of our findings supported that worrisome notion. In addition, EE practitioners should consider the ethical implications of manipulating audiences' emotional states. As evident from prior attempts to manipulate emotions, such as in the infamous case of a recent Facebook experiment (Kramer, Guillory, \& Hancock, 2014), people are enraged and hurt when learning their emotions were played with by researchers. Once again, we recommend EE researchers and practitioners to practice respect and compassion toward audiences' emotions when crafting such stories.

Emotional flow remains a promising, if currently under-explored, vehicle for increasing the effectiveness of EE stories. If supported empirically through additional research, emotional flow could become a staple of future EE stories. In the meantime, however, existing data offer only limited support for this intriguing idea, at least in the context of relatively short, text-based EE stories.

\section{REFERENCES}

Archer, J., \& Jockers, M. L. (2016). The bestseller code: Anatomy of the blockbuster novel. Syuzhet: St. Martin's Press.

Bandura, A. (1986). Social foundations of thought and action: A social cognitive theory: Vol. xiii. Englewood Cliffs: Prentice-Hall.

Bechara, A., Damasio, H., \& Damasio, A. R. (2000). Emotion, decision making and the orbitofrontal cortex. Cerebral Cortex, 10(3), 295-307. https://doi. org/10.1093/cercor/10.3.295

Berlyne, D. E. (1960). Conflict, arousal, and curiosity. New York: McGraw-Hill Book Company. https://doi.org/10.1037/11164-000

Brehm, S. S., \& Brehm, J. W. (1981). Psychological reactance-A theory of freedom and control. New York: Academic Press.

Busselle, R., \& Bilandzic, H. (2009). Measuring narrative engagement. Media Psychology, 12(4), 321-347. https://doi.org/10.1080/15213260903287259

Cappella, J. N., Maloney, E., Ophir, Y., \& Brennan, E. (2015). Interventions to correct misinformation about tobacco products. Tobacco Regulatory Science, I(2), 186-197. https://doi.org/10.18001/TRS.1.2.8 
Cho, H., Shen, L., \& Wilson, K. (2012). Perceived realism: Dimensions and roles in narrative persuasion. Communication Research, 41(6), 828-851. https:// doi.org/10.1177/0093650212450585

Cohen, J. (2001). Defining identification: A theoretical look at the identification of audiences with media characters. Mass Communication and Society, 4(3), 245-264. https://doi.org/10.1207/S15327825MCS0403_01

DeSteno, D., Gross, J. J., \& Kubzansky, L. (2013). Affective science and health: The importance of emotion and emotion regulation. Health Psychology, 32(5), 474-486. https://doi.org/10.1037/a0030259

Dillard, J. P., \& Nabi, R. L. (2006). The persuasive influence of emotion in cancer prevention and detection messages. Journal of Communication, 56, 123-139. https://doi.org/10.1111/j.1460-2466.2006.00286.x

Dunlop, S., Wakefield, M., \& Kashima, Y. (2008). Can you feel it? Negative emotion, risk, and narrative in health communication. Media Psychology, 11(1), 52-75. https://doi.org/10.1080/15213260701853112

Eagly, A. H., \& Chaiken, S. (1993). The psychology of attitudes. Fort Worth: Harcourt Brace Jovanovich College Publishers.

Festinger, L. (1962). A theory of cognitive dissonance. Stanford: Stanford University Press.

Fitzgerald, K., Paravati, E., Green, M. C., Moore, M. M., \& Qian, J. L. (2019). Restorative narratives for health promotion. Health Communication, 0(0), 1-8. https://doi.org/10.1080/10410236.2018.1563032

Gao, J., Jockers, M. L., Laudun, J., \& Tangherlini, T. (2016). A multiscale theory for the dynamical evolution of sentiment in novels. 6 International Conference on Behavioral, Economic and Socio-Cultural Computing, Durham, NC. http://www.gao.ece.ufl.edu/my_paper/sentiment_BESC2016.pdf

Gerrig, R. J. (1993). Experiencing narrative worlds: On the psychological activities of reading. New Haven: Yale University Press.

de Graaf, A., Hoeken, H., Sanders, J., \& Beentjes, J. W. J. (2012). Identification as a mechanism of narrative persuasion. Communication Research, 39(6), 802-823. https://doi.org/10.1177/0093650211408594

Gratale, S. K., Maloney, E. K., Sangalang, A., \& Cappella, J. N. (2017). Influence of Natural American Spirit advertising on current and former smokers' perceptions and intentions. Tobacco Control, tobaccocontrol-2017-053881. https:// doi.org/10.1136/tobaccocontrol-2017-053881

Gratale, S. K., Sangalang, A., Maloney, E. K., \& Cappella, J. N. (2019). Attitudinal spillover from misleading natural cigarette marketing: An experiment examining current and former smokers' support for tobacco industry regulation. International Journal of Environmental Research and Public Health, 16(19), 3554. https://doi.org/10.3390/ijerph16193554

Green, M. C., \& Brock, T. C. (2000). The role of transportation in the persuasiveness of public narratives. Journal of Personality and Social Psychology, 79(5), 701-721. https://doi.org/10.1037/0022-3514.79.5.701 
Guido, G., Pichierri, M., \& Pino, G. (2018). Place the good after the bad: Effects of emotional shifts on consumer memory. Marketing Letters, 29(1), 49-60. https://doi.org/10.1007/s11002-017-9439-0

Jose, P. E., \& Brewer, W. F. (1984). Development of story liking: Character identification, suspense, and outcome resolution. Developmental Psychology, 20(5), 911-924. https://doi.org/10.1037/0012-1649.20.5.911

Kim, M., Shi, R., \& Cappella, J. N. (2016). Effect of character-audience similarity on the perceived effectiveness of antismoking psas via engagement. Health Communication, 31(10), 1193-1204. https://doi.org/10.1080/1041023 6.2015.1048421

Kramer, A. D. I., Guillory, J. E., \& Hancock, J. T. (2014). Experimental evidence of massive-scale emotional contagion through social networks. Proceedings of the National Academy of Sciences, 111(24), 8788-8790. https://doi. org/10.1073/pnas.1320040111

Lewandowsky, S., Ecker, U. K. H., Seifert, C. M., Schwarz, N., \& Cook, J. (2012). Misinformation and its correction: Continued influence and successful debiasing. Psychological Science in the Public Interest, 13(3), 106-131. https://doi. org/10.1177/1529100612451018

Malson, J. L., Lee, E. M., Moolchan, E. T., \& Pickworth, W. B. (2002). Nicotine delivery from smoking bidis and an additive-free cigarette. Nicotine $\&$ Tobacco Research, 4(4), 485-490. https://doi.org/10.1080/1462220021000018498

Mazzocco, P. J., Green, M. C., Sasota, J. A., \& Jones, N. W. (2010). This story is not for everyone: Transportability and narrative persuasion. Social Psychological and Personality Science, 1(4), 361-368. https://doi. org/10.1177/1948550610376600

McAllister, C. (2020). Emotions in motion: The role of emotional flow in narrative persuasion. Buffalo: University at Buffalo.

Moyer-Gusé, E. (2008). Toward a theory of entertainment persuasion: Explaining the persuasive effects of entertainment-education messages. Communication Theory, 18(3),407-425.https://doi.org/10.1111/j.1468-2885.2008.00328.x

Moyer-Gusé, E., Chung, A. H., \& Jain, P. (2011). Identification with characters and discussion of taboo topics after exposure to an entertainment narrative about sexual health. Journal of Communication, 61(3), 387-406. https://doi. org/10.1111/j.1460-2466.2011.01551.x

Murphy, S. T., Frank, L. B., Moran, M. B., \& Patnoe-Woodley, P. (2011). Involved, transported, or emotional? Exploring the determinants of change in knowledge, attitudes, and behavior in entertainment-education. Journal of Communication, 61(3), 407-431. https://doi.org/10.1111/j.1460-2466.2011.01554.x

Nabi, R. L. (1999). A cognitive-functional model for the effects of discrete negative emotions on information processing, attitude change, and recall. Communication Theory, 9, 292-320. https://doi.org/10.1111/j.14682885.1999.tb00172.x 
Nabi, R. L. (2002). Discrete Emotions and Persuasion. In J. P. Dillard, \& M. Pfau (Eds.), The Persuasion Handbook: Developments in Theory and Practice (pp. 289-308). SAGE Publications. http://sk.sagepub.com/reference/hdbk_ persuasion/n15.xml

Nabi, R. L., \& Green, M. C. (2014). The role of a narrative's emotional flow in promoting persuasive outcomes. Media Psychology, 18(2), 1-26. https://doi. org/10.1080/15213269.2014.912585

Nummenmaa, L., Glerean, E., Hari, R., \& Hietanen, J. K. (2014). Bodily maps of emotions. Proceedings of the National Academy of Sciences, 111(2), 646-651. https://doi.org/10.1073/pnas.1321664111

Oatley, K. (2002). Emotions and the story worlds of fiction. In Narrative impact: Social and cognitive foundations2a (pp. 39-70).

Oatley, K. (2012). The passionate muse: Exploring emotion in stories. Oxford: Oxford University Press.

O'Keefe, D. J. (2013). The relative presuasiveness of different forms of argumentsfrom-consequences: A review and integration. Annals of the International Communication Association, 36(1), 109-135.

Ophir, Y., Brennan, E., Maloney, E. K., \& Cappella, J. N. (2017). The effects of graphic warning labels' vividness on message engagement and intentions to quit smoking. Communication Research, 46(5), 619-638. https://doi. org/10.1177/0093650217700226

Ortony, A., Clore, G. L., \& Collins, A. (1990). The cognitive structure of emotions. Cambridge: Cambridge University Press.

Poindexter, D. (2004). A history of entertainment-education, 1958-2000. In A. Singhal, M. J. Cody, E. M. Rogers, \& M. Sabido (Eds.), Entertainmenteducation and social change: History, research, and practice (pp. 21-38). Mahwah: Lawrence Erlbaum Associates.

Ray, E. C., Arpan, L., Oehme, K., Perko, A., \& Clark, J. (2019). Testing restorative narratives in a college student resilience project. Innovative Higher Education, 44(4), 267-282. https://doi.org/10.1007/s10755-019-9464-4

Rossiter, J. R., \& Thornton, J. (2004). Fear-pattern analysis supports the feardrive model for antispeeding road-safety TV ads. Psychology \& Marketing, 21(11), 945-960. https://doi.org/10.1002/mar.20042

Royzman, E. B., \& Rozin, P. (2006). Limits of symhedonia: The differential role of prior emotional attachment in sympathy and sympathetic joy. Emotion (Washington, D.C.), 6(1), 82-93. https://doi.org/10.1037/ 1528-3542.6.1.82

Sangalang, A., Ophir, Y., \& Cappella, J. N. (2019). The potential for narrative correctives to combat misinformation. Journal of Communication, 69(3), 298-319. https://doi.org/10.1093/joc/jqz014

Scheff, T. J. (1979). Catharsis in healing, ritual, and drama. California: University of California Press. 
Shen, F., Sheer, V. C., \& Li, R. (2015). Impact of narratives on persuasion in health communication: A meta-analysis. Journal of Advertising, 44(2), 105-113. https://doi.org/10.1080/00913367.2015.1018467

Slater, M. D., \& Rouner, D. (2002). Entertainment-education and elaboration likelihood: Understanding the processing of narrative persuasion. Communication Theory, 12(2), 173-191. https://doi.org/10.1111/ j.1468-2885.2002.tb00265.x

Tal-Or, N., \& Cohen, J. (2010). Understanding audience involvement: Conceptualizing and manipulating identification and transportation. Poetics, 38(4), 402-418. https://doi.org/10.1016/j.poetic.2010.05.004

Wang, H., \& Singhal, A. (2016). East los high: Transmedia edutainment to promote the sexual and reproductive health of young latina/o americans. American Journal of Public Health, 106(6), 1002-1010. https://doi.org/10.2105/ AJPH.2016.303072

Witte, K. (1992). Putting the fear back into fear appeals: The extended parallel process model. Communication Monographs, 59(4), 329-349. https://doi. org/10.1080/03637759209376276

Witte, K., \& Allen, M. (2000). A meta-analysis of fear appeals: Implications for effective public health campaigns. Health Education \& Behavior, 27(5), 591-615. https://doi.org/10.1177/109019810002700506

Open Access This chapter is licensed under the terms of the Creative Commons Attribution-NonCommercial-NoDerivatives 4.0 International License (http:// creativecommons.org/licenses/by-nc-nd/4.0/), which permits any noncommercial use, sharing, distribution and reproduction in any medium or format, as long as you give appropriate credit to the original author(s) and the source, provide a link to the Creative Commons licence and indicate if you modified the licensed material. You do not have permission under this licence to share adapted material derived from this chapter or parts of it.

The images or other third party material in this chapter are included in the chapter's Creative Commons licence, unless indicated otherwise in a credit line to the material. If material is not included in the chapter's Creative Commons licence and your intended use is not permitted by statutory regulation or exceeds the permitted use, you will need to obtain permission directly from the copyright holder.

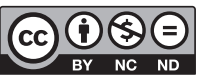

